\title{
Treatment with 6-Hydroxydopamine and Colchicine Decreases Nerve Growth Factor Levels in Sympathetic Ganglia and Increases Them in the Corresponding Target Tissues ${ }^{1}$
}

\author{
SIGRUN KORSCHING AND HANS THOENEN² \\ Max-Planck-Institute for Psychiatry, Department of Neurochemistry, D-8033 Martinsried, West Germany
}

\begin{abstract}
A two-site enzyme immunoassay was used to determine the nerve growth factor (NGF) contents of sympathetic ganglia and their corresponding target tissues in adult rats.

The destruction of sympathetic nerve terminals by 6-hydroxydopamine (6-OHDA) and the blockade of axonal transport by colchicine resulted in a rapid increase in the NGF levels of sympathetically innervated organs and a rapid decrease in the sympathetic ganglia. NGF levels in heart atrium, heart ventricle, submandibular gland, and iris increased 2- to 4-fold $12 \mathrm{hr}$ after injection of 6-OHDA, whereas the NGF contents of stellate and superior cervical ganglia dropped to a minimal level of 3 to $4 \%$ of control $24 \mathrm{hr}$ after injection. Twelve hours after treatment with colchicine the NGF levels in sympathetically innervated organs increased 2- to 3-fold, whereas the NGF contents of sympathetic ganglia fell to onethird of control values. The half-lives of NGF in the superior cervical and stellate sympathetic ganglia were 4.5 and 4.8 $\mathrm{hr}$, respectively, as determined by the decrease of NGF content after treatment with 6-OHDA.

These results indicate that the synthesis of NGF is normally confined to the innervated target organs with no significant contribution of ganglionic cells. This is consistent with the concept that NGF acts as a retrograde messenger between target organs and innervating sympathetic neurons.
\end{abstract}

Nerve growth factor (NGF) is thought to act as a retrograde trophic messenger between peripheral target organs and innervating sympathetic and sensory neurons (see Thoenen and Barde, 1980; Bradshaw, 1983; Schwab and Thoenen, 1983). Previously this concept was based only on indirect evidence, since the reliable determination of in vivo NGF levels was essentially restricted to the extremely rich NGF sources such as the mouse submandibular gland and the accessory sex glands of several species. These were shown not to be relevant for the neurotrophic action of NGF: the rich sources are exocrine glands, whose NGF contents are sex and species specific, whereas NGF-responsive neurons are present in all higher vertebrates of either sex studied so far (see Thoenen and Barde, 1980; Bradshaw, 1983). The recent development of a sensitive immunoassay for NGF allowed the determination of endoge-

Received June 5, 1984; Revised September 10, 1984; Accepted October 8, 1984

\footnotetext{
${ }^{1}$ We wish to thank G. P. Harper for the monoclonal antibody against mouse nerve growth factor, D. Edgar for critical review of the manuscript, and $A$. Brandhofer and F. Scholz-Marb for their excellent technical assistance.

${ }^{2}$ To whom correspondence should be addressed.
}

nous NGF levels in several target tissues of sympathetic neurons (Korsching and Thoenen, 1983a; Thoenen et al., 1983). These NGF levels were correlated with the density of sympathetic innervation, and the sympathetic ganglia contained the highest NGF levels of all tissues studied. Furthermore, ligation of the sciatic nerve (containing sensory and sympathetic axons) resulted in a rapid accumulation of NGF at the distal side of the ligature, providing direct evidence for the retrograde axonal transport of endogenous NGF (Korsching and Thoenen, 1983b). Together with the necessity of retrograde transport for survival and maintenance of function of sympathetic neurons (see Schwab and Thoenen, 1983), these findings indicate that the peripheral target organs are the major source of NGF required by the sympathetic neurons.

However, the importance of retrograde axonal transport for the NGF levels in sympathetic ganglia and corresponding target tissues could not be deduced from these experiments: it was unclear to what extent retrograde axonal transport reduced the NGF levels in target tissues and to what extent the high levels of NGF in sympathetic ganglia were due to the supply from the periphery or alternatively were caused by synthesis within the ganglia.

In order to answer these questions we investigated the changes in NGF levels resulting from the interruption of retrograde transport by either destruction of sympathetic nerve terminals with 6-hydroxydopamine (6.OHDA) (see Thoenen, 1972), or blockade of fast axonal transport by colchicine (Kreutzberg, 1969).

\section{Materials and Methods}

Enzyme immunoassay for determination of NGF. The NGF contents of sympathetic ganglia and peripheral target tissues were determined by a two. site enzyme immunoassay that can detect $0.2 \mathrm{pg}$ of NGF/assay $(0.01 \mathrm{fmol}$ of NGF/assay). The details of the method have been published elsewhere (Korsching and Thoenen, 1983a). Briefly, the samples were homogenized in 4 to $50 \mathrm{vol}$ of $0.1 \mathrm{M}$ Tris $\mathrm{HCl}$ buffer, $\mathrm{pH} 7.0$, containing $2 \%$ bovine serum albumin, $2 \%$ gelatin, $0.4 \mathrm{M} \mathrm{NaCl}$, and protease inhibitors. The homogenates were centrifuged at $100,000 \times g$, and the supernatants were diluted $1: 1$ with $0.2 \%$ Triton $\mathrm{X}-100$ and incubated over night at room temperature with the monoclonal anti-mouse NGF antibody, 27/21, covalently linked to 1-mmdiameter glass beads. The bound NGF was detected by a $2 \cdot \mathrm{hr}$ incubation at $37^{\circ} \mathrm{C}$ with a second, $\beta$-galactosidase-labeled anti-NGF antibody ( $\beta$-galactosidase, Boehringer Mannheim). Bound enzyme was then quantified by the generation of fluorescent 4-methylumbelliferone from 4-methylumbelliferyl- $\beta$ D-galactoside. The NGF content is expressed as equivalents of mouse 2.5 SNGF and corrected for the recovery of added mouse NGF, which amounted to 40 to $100 \%$, depending on the tissue. The recovery was determined in each experiment at exogenous NGF concentrations of 0.1 to $0.2 \mathrm{ng} / \mathrm{ml}$ and was not affected by the drug treatment. NGF levels in tissues from drug treated animals were normalized as percentage of control and refer to control tissues measured in the same experiment to minimize interassay variances.

Drug treatment. Wistar rats of both sexes (150 to $200 \mathrm{gm}$ ) were anesthe tized with ether and then injected intraperitoneally with freshly dissolved drugs.

6-OHDA hydrobromide was dissolved in $13 \mathrm{~mm} \mathrm{Na}_{2} \mathrm{HPO}_{4}, 1.5 \mathrm{~mm} \mathrm{KH}_{2} \mathrm{PO}_{4}$ $140 \mathrm{mM} \mathrm{NaCl}, 3 \mathrm{mM} \mathrm{KCl}$ (PBS) $+1.5 \mathrm{mg} / \mathrm{ml}$ of ascorbic acid (Merck) and 
used at a dose of $100 \mathrm{mg}$ of 6-OHDA (free base) $/ \mathrm{kg}$ of body weight (see Thoenen, 1972). Ascorbic acid was added to protect 6-OHDA against oxidation. Control rats were injected with PBS $+1.5 \mathrm{mg} / \mathrm{ml}$ of ascorbic acid. Only those experimental rats with strong sympathomimetic effects (piloerection and exophthalmos) were used for determination of NGF content, in order to exclude animals with a poor resorption of 6-OHDA. The sympathetic reactions began as early as $3 \mathrm{~min}$ after injection and continued for up to 3 $\mathrm{hr}$. Subsequently, eyelid closure was virtually complete between 6 and $36 \mathrm{hr}$ after injection of 6-OHDA, indicating the absence of sympathetic transmission. Forty-eight hours after injection, the eyelid position was practically normal again, indicating the restoration of sympathetic transmission, which probably results from the development of supersensitivity to residual transmitter substances in the target organs (see Thoenen, 1972). The rats were killed by cervical dislocation $3,12,24$, and $48 \mathrm{hr}$ after 6-OHDA injection, and the tissues to be assayed were dissected and frozen on dry ice.

Colchicine was dissolved in PBS, and 1 to $10 \mathrm{mg} / \mathrm{kg}$ of body weight were injected intraperitoneally. Control rats received PBS alone. Mortality reached $30 \%$ at the highest dose used. The rats were killed by cervical dislocation $12 \mathrm{hr}$ after injection.

Reagents. If not otherwise stated, all reagents were obtained from Sigma Chemical Co.

\section{Results}

Changes of NGF levels after 6-OHDA treatment. After a single injection of 6-OHDA, a rapid increase in the NGF content of sympathetically innervated organs occurred (Fig. 1, $a$ and b). After $3 \mathrm{hr}$, the NGF content of heart atrium and submandibular gland was already significantly increased ( $p<0.01$ ). After $12 \mathrm{hr}$, a 2 - to 4 -fold increase of NGF content above control was observed in all sympathetically innervated organs studied. Between 12 and $48 \mathrm{hr}$, the NGF levels remained constant in heart atrium and submandibular gland, whereas in heart ventricle and iris the NGF levels continued to increase.

The NGF content of both the stellate and superior cervical sympathetic ganglia decreased within $24 \mathrm{hr}$ to 3 to $4 \%$ of control values (Fig. 2). Between 24 and $48 \mathrm{hr}$ after 6-OHDA injection, the NGF content in both ganglia increased again to 20 to $25 \%$ of control values. To test whether this increase was due to partial regeneration of the terminals of lesioned sympathetic neurons, a second dose of 6-OHDA was injected after $48 \mathrm{hr}$. However, $24 \mathrm{hr}$ after the second injection, the NGF content of the sympathetic ganglia remained at 23 and $27 \%$ of control values (stellate and superior cervical ganglion, respectively).

The degradation rate of NGF in the sympathetic ganglia was calculated from the time course of NGF decrease between 3 and $24 \mathrm{hr}$ after 6-OHDA injection. The NGF contents were plotted semilogarithmically over the time after injection (Fig. 2). With this plot, small lag phases of about 1.5 and $0.5 \mathrm{hr}$ became apparent (stellate ganglion and superior cervical ganglion, respectively). This may be explained by the transport of residual axonal NGF to the ganglia after destruction of the terminals. The half-lives of NGF in these two ganglia were similar, i.e., $4.5 \mathrm{hr}$ for the superior cervical and $4.8 \mathrm{hr}$ for the stellate ganglion.

Changes of NGF levels after colchicine treatment. The effects of colchicine on the NGF levels in sympathetically innervated organs and sympathetic ganglia were similar to that of 6-OHDA. At the highest dose tolerated (10 mg/kg of body weight), the NGF content of sympathetically innervated organs increased to 150 to $300 \% 12$ $\mathrm{hr}$ after injection, whereas the NGF levels in sympathetic ganglia decreased to one-third of control values (Table I). With $1 \mathrm{mg}$ of colchicine $/ \mathrm{kg}$ of body weight, however, no significant changes in NGF levels were observed with exception of the superior cervical ganglion $(p<0.03$ ).

\section{Discussion}

To determine to what extent NGF levels in the target organs were influenced by retrograde axonal transport and whether the high levels of NGF found in sympathetic ganglia resulted from retrograde transport or local synthesis by non-neuronal cells in the ganglia, both $6-O H D A$ and colchicine were administered to adult rats to prevent
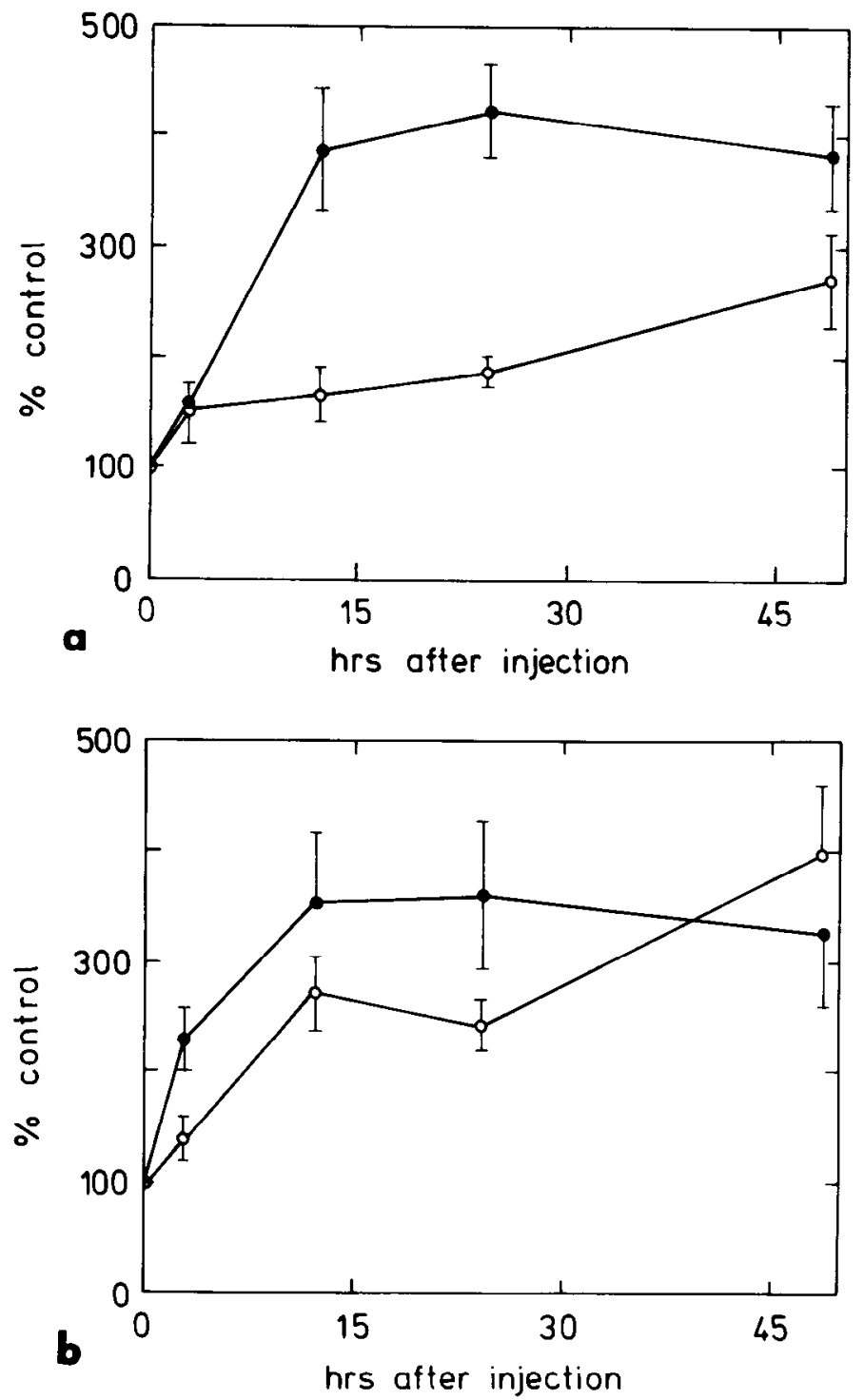

Figure 1. NGF levels in target tissues after 6-OHDA injection. NGF content was measured by two-site enzyme immunoassay and expressed as percentage of control (mean control values; see Table I). Indicated are mean values \pm SEM of two to three independent experiments, each including quadruplicate determinations. Tissues of three animals were pooled for each experiment. $a$, Organs innervated by the superior cervical ganglion. $\mathbf{0}$, submandibular gland; $O$, iris. $b$, Organs innervated by the stellate ganglion. - heart atrium; $O$ heart ventricle.

the retrograde transport of NGF from target tissues to the cell bodies of their innervating neurons. Both drugs increased the NGF content of sympathetic target organs, suggesting strongly that NGF is synthesized there and that NGF levels are kept low by continuous removal by the innervating sympathetic neurons. The increase of NGF content in sympathetically innervated organs after colchicine treatment was generally not as high as that seen after 6-OHDA. This could well be because the highest colchicine dose tolerated by the rats did not completely block axonal transport. The comparatively large NGF increase in the iris after colchicine treatment possibly reflects the presence of the relatively dense sensory innervation (Miller et al., 1981; Seiger et al., 1984) of the iris: colchicine treatment eliminates removal of NGF by sympathetic and sensory axons, whereas after 6-OHDA treatment the remaining sensory terminals may even be capable of enhanced removal of NGF as indicated by an increase in NGF content in the spinal ganglia (unpublished observation). This is probably also the cause for the increase of 


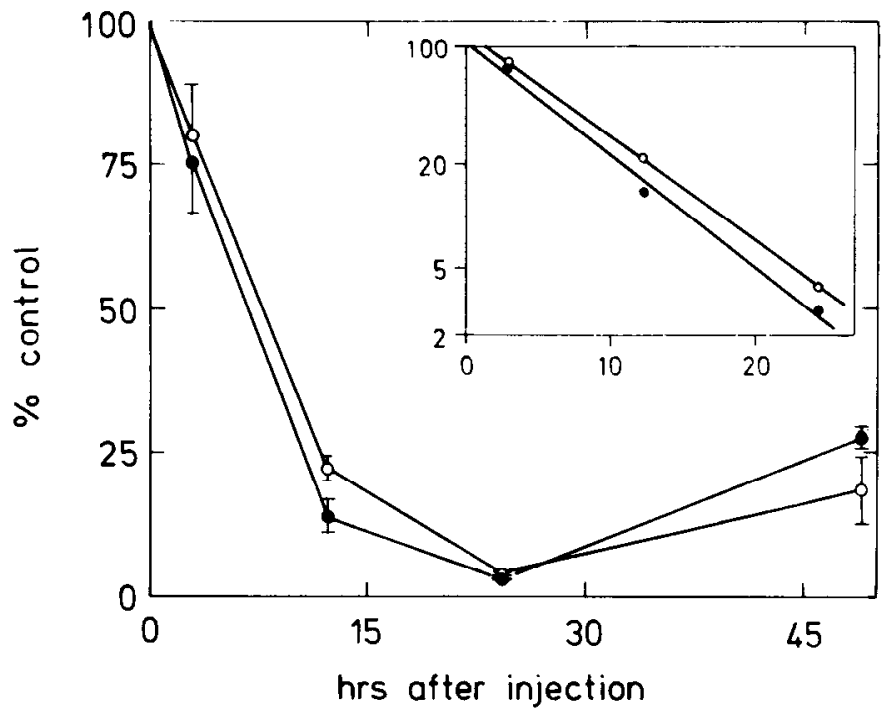

Figure 2. NGF levels in sympathetic ganglia after 6-OHDA injection. NGF content was measured by two-site enzyme immunoassay and expressed as percentage of control (mean control values; see Table l). Indicated are mean values \pm SEM of two to three independent experiments, each including quadruplicate determinations. Tissues of three animals were pooled for each experiment. The inset shows the time course during the first $24 \mathrm{hr}$ after injection with a semilogarithmic scale. 0 , superior cervical ganglion; $O$ stellate ganglion.

TABLE ।

Influence of colchicine on NGF content in vivo

Values are means \pm SEM. The NGF content of control organs was not significantly different between colchicine and 6-OHDA experiments and did not depend on the time after injection. The pooled control values $(n=11)$ are: $3.0 \pm 0.5 \mathrm{ng}$ of NGF/gm of wet weight (iris), $1.5 \pm 0.2$ (submandibular gland), $0.85 \pm 0.13$ (heart atrium), $0.28 \pm 0.06$ (heart ventricle), $44 \pm 6$ (superior cervical ganglion), and $27 \pm 6$ (stellate ganglion).

\begin{tabular}{lrr} 
& \multicolumn{2}{c}{ NGF levels (\% control) } \\
\cline { 2 - 3 } \multicolumn{1}{c}{ Organ } & \multicolumn{2}{c}{ Colchicine } \\
\cline { 2 - 3 } & $1 \mathrm{mg} / \mathrm{kg}$ & $10 \mathrm{mg} / \mathrm{kg}$ \\
\hline Iris & $125 \pm 28$ & $305 \pm 43^{a}$ \\
Submandibular gland & $89 \pm 17$ & $176 \pm 25^{a}$ \\
Heart atrium & $95 \pm 19$ & $296 \pm 36^{a}$ \\
Heart ventricle & $102 \pm 31$ & $150 \pm 35$ \\
Superior cervical ganglion & $72 \pm 9^{b}$ & $31 \pm 4^{a}$ \\
Stellate ganglion & $87 \pm 12$ & $34 \pm 5^{a}$ \\
\hline
\end{tabular}

a Significantly different from control $(p<0.01)$.

b Significantly different from control $(p<0.03)$.

substance $P$ in the iris after sympathetic denervation (Kessler et al., 1983). This interpretation agrees with the results of Ebendal et al. (1983), who showed that an increase in NGF activity of the iris was barely detectable after sympathetic denervation, whereas the combined sympathetic and sensory denervation resulted in a much higher increase.

The accumulation of NGF in target tissues after 6-OHDA injection may not only be due to lack of NGF removal via retrograde transport but may also reflect an increased rate of synthesis that may be influenced by the presence or activity of the sympathetic nerve terminals. Such an increase in the rate of NGF synthesis was observed in rat irides, which were denervated by being brought into culture (Barth et al., 1984). The constant increase of NGF levels in heart ventricle and iris during the whole observation period could be due to an induction (or removal of inhibition) of NGF synthesis. No obvious induction of NGF synthesis was seen, however, in heart atrium and submandibular gland, where NGF levels were maximal already $12 \mathrm{hr}$ after injection. With an unchanged rate of synthesis of
NGF, the new equilibrium between production and removal of NGF via diffusion would be expected to be established rapidly.

The reduction of NGF levels in the sympathetic ganglia to less than $5 \% 24 \mathrm{hr}$ after 6 -OHDA treatment shows that local NGF synthesis in the ganglia does not contribute significantly to their NGF content under normal circumstances. This is paralleled by the finding that the NGF content in rat sciatic nerves drastically falls proximal to a lesion (Korsching and Thoenen, 1983b), excluding a significant contribution to the NGF synthesis by non-neuronal cells of the nerve. It is unlikely that the observed decrease of ganglionic NGF content is caused by direct toxic effects of 6-OHDA or colchicine, since these two drugs have different mechanisms of action and the NGF levels in target organs already increased $3 \mathrm{hr}$ after injection of 6 OHDA. Therefore, we conclude that the decrease of NGF content in sympathetic ganglia observed after treatment with either 6-OHDA or colchicine results in both cases from the interruption of transport between target organs and neuronal cell bodies.

It can be deduced from our results that glial cells and fibroblasts in sympathetic ganglia (and in peripheral nerve; see Korsching and Thoenen, 1983b) do not produce significant amounts of NGF. It should be noted, however, that the partial recovery of ganglionic NGF content between 24 and $48 \mathrm{hr}$ after injection of 6-OHDA was not influenced by a second 6-OHDA injection. Thus, NGF synthesis might be induced in ganglionic non-neuronal cells as part of the response of ganglionic cells to axotomy (cf. Schwab and Thoenen, 1983). This induction may be compared to that of sciatic nerve, which does not contribute significantly to NGF synthesis in vivo (Korsching and Thoenen, 1983b), but synthesizes NGF in vitro (Richardson and Ebendal, 1982). However, the possible NGF synthesis in ganglia and nerves is not sufficient to sustain neonatal sympathetic neurons after interruption of retrograde axonal transport, in contrast to exogenous, added NGF (Levi-Montalcini et al., 1975). In addition, it is still conceivable that in partly damaged neurons the NGF uptake system is restored earlier than the catecholamine uptake systern, the latter being the prerequisite for the destruction of these terminals by a second dose of 6-OHDA.

The half-life of ganglionic NGF was determined to be in the range of 4.5 to $4.8 \mathrm{hr}$. This determination depends on the assumption that uptake of NGF is inhibited almost immediately after 6-OHDA injection, which seems plausible in view of the almost immediate sympathomimetic reaction and the observed exponential decrease of NGF content in the sympathetic ganglia. Degradation of exogenous, labeled NGF has been studied in the superior cervical ganglion after intraocular injection of ${ }^{125}$-NGF (Stöckel et al., 1975; Johnson et al., 1978). However, these data are not comparable to our results, since there the degradation of NGF could not be studied independent of receptor binding and uptake. Pheochromocytoma (PC12) cells degrade NGF rapidly (Layer and Shooter, 1983), with a half-life of about $1 \mathrm{hr}$ (Heumann et al., 1984).

During preparation of this paper, Yap et al. (1984) reported that, after 6-OHDA injection, a survival activity for sympathetic neurons appeared in rat heart tissue, which could be blocked by antiserum to NGF. This observation agrees with our results. A direct comparison of their data is not possible, however, since their first measurements were made 4 days after 6-OHDA injection, whereas we measured tissue levels of NGF between 3 and $48 \mathrm{hr}$ after injection. In addition, the relative increase cannot be deduced from their data, since the NGF activity in untreated heart tissue is below the detection limit of the biological assay.

In conclusion, our results indicate that, under physiological conditions, most of the NGF required by sympathetic neurons is synthesized in their peripheral target tissues and that the high NGF levels in sympathetic ganglia result from retrograde axonal transport rather than from local synthesis.

\section{References}

Barth, E. -M., S. Korsching, and H. Thoenen (1984) Regulation of nerve growth factor synthesis and release in organ cultures of rat iris. J. Cell Biol. 99: 839-843. 
Bradshaw, R. A. (1983) Nerve growth factor and related hormones. In Biochemical Actions of Hormones, G. Litwack, ed., Vol. 10, pp. 91-114, Academic Press, Inc., New York

Ebendal, T., L. Olson, and A. Seiger (1983) The level of nerve growth factor (NGF) as a function of innervation. Exp. Cell Res. 148: 311-317.

Heumann, R., M. Schwab, R. Merkl, and H. Thoenen (1984) Nerve growth factor-mediated induction of choline acetyltransferase in PC12 cells: Evaluation of the site of action of nerve growth factor and the involvement of Iysosomal degradation products of nerve growth factor. J. Neurosci. 4: 3039-3050.

Johnson, E. M., R. Y. Andres, and R. A. Bradshaw (1978) Characterization of the retrograde transport of nerve growth factor using high specific activity $\left({ }^{125}\right.$ I) nerve growth factor. Brain Res. 150: 319-331.

Kessler, J. A., W. O. Bell, and I. B. Black (1983) Interactions between the sympathetic and sensory innervation of the iris. J. Neurosci. 3: 13011307.

Korsching, S., and H. Thoenen (1983a) Nerve growth factor in sympathetic ganglia and corresponding target organs of the rat: Correlation with density of sympathetic innervation. Proc. Natl. Acad. Sci. U. S. A. 80: 3513-3516.

Korsching, S., and $H$. Thoenen (1983b) Quantitative demonstration of the retrograde axonal transport of endogenous nerve growth factor. Neurosci. Lett. 39; 1-4.

Kreutzberg, G. W. (1969) Neuronal dynamics and axonal flow. IV. Blockage of intra-axonal enzyme transport by colchicine. Proc. Natl. Acad. Sci. U. S. A. 62: 722-728.

Layer, P. G., and E. M. Shooter (1983) Binding and degradation of nerve growth factor by PC12 pheochromocytoma cells. J. Biol. Chem. 258: 3012-3018.
Levi-Montalcini, R., L. Aloe, E. Mugnaini, F. Oesch, and H. Thoenen (1975) Nerve growth factor induces volume increase and enhances tyrosine hydroxylase synthesis in chemically axotomized sympathetic ganglia of newborn rats. Proc. Natl. Acad. Sci. U. S. A. 72: 595-599.

Miller, A., M. Costa, J. B. Furness, and I. W. Chubb (1981) Substance P immunoreactive sensory nerves supply the rat iris and cornea. Neurosci. Lett. 23: 243-249.

Richardson, P. M., and T. Ebendal (1982) Nerve growth activities in rat peripheral nerve. Brain Res. 246: 57-64.

Schwab, M. E., and H. Thoenen (1983) Retrograde axonal transport. In Handbook of Neurochemistry, Ed. 2, A. Lajtha, ed., Vol. 5, pp. 381-404, Plenurn Press, New York.

Seiger, A., D. Dahl, C. Ayer-LeLievre, and H. Björklund (1984) Appearance and distribution of neurofilament immunoreactivity in iris nerves. J. Comp. Neurol. 223: 457-470.

Stöckel, K., M. E. Schwab, and H. Thoenen (1975) Comparison between the retrograde axonal transport of nerve growth factor and tetanus toxin in motor, sensory and adrenergic neurons. Brain Res. 99: 1-16.

Thoenen, H. (1972) Surgical, immunological and chemical sympathectomy. In Handbook of Experimental Pharmacology, H. Blaschko and E. Muscholl, eds., Vol. 33, pp. 813-844, Springer, Berlin.

Thoenen, $H_{\text {., }}$ and $Y$. $-A$. Barde (1980) Physiology of nerve growth factor Physiol. Rev. 60: 1284-1335.

Thoenen, H., S. Korsching, Y. -A. Barde, and D. Edgar (1983) Quantitation and purification of neurotrophic molecules. Cold Spring Harbor Symp. Quant. Biol. 48: 679-684.

Yap, H. B., I. A. Hendry, C. E. Hill, and D. J. Watters (1984) Effects of cardiac denervation on levels of neuronal survival factors for cultured autonomic neurones. Dev. Brain Res. 12: 154-157. 